\title{
Testing for context-dependent effects of maternal thyroid hormones on offspring survival and physiology: an experimental approach manipulating temperature in a wild bird species
}

\author{
Bin-Yan Hsu*1, Tom Sarraude ${ }^{2}$, Nina Cossin-Sevrin ${ }^{1}$, Melanie Crombecque ${ }^{1}$, Antoine Stier ${ }^{\S 1,3}$ \& Suvi \\ Ruuskanen ${ }^{\$ 1}$ \\ ${ }^{1}$ Section of Ecology, Department of Biology, University of Turku, Finland \\ ${ }^{2}$ GELIFES, University of Groningen, The Netherlands \\ ${ }^{3}$ Institute of Biodiversity, Animal Health, and Comparative Medicine, University of Glasgow, UK \\ \$shared last authorship \\ *corresponding author: biyahs@utu.fi
}

\section{Abstract}

Maternal effects via hormonal transfer from the mother to the offspring provide a tool to translate environmental cues to the offspring. Experimental manipulations of maternally transferred hormones have yielded increasingly contradictory results, which may be explained by environment-dependent effects of hormones. Yet context-dependent effects have rarely been experimentally tested. We therefore studied whether maternally transferred thyroid hormones (THs) exert context-dependent effects on offspring survival and physiology by manipulating both egg TH levels and post-hatching nest temperature in wild pied flycatchers (Ficedula hypoleuca) using a full factorial design. We found no clear evidence for context-dependent effects of prenatal THs related to postnatal temperature on growth, survival and potential underlying physiological responses (plasma TH levels, oxidative stress and mitochondrial density). We conclude that future studies should test for other key environmental conditions, such as food availability, to understand potential context-dependent effects of maternally transmitted hormones on offspring, and their role in adapting to changing environments.

Keywords: parental effects, climate change, ecophysiology, developmental temperature, thyroid hormones 


\section{Introduction}

Maternal effects may translate environmental cues from the mother to the offspring for example via maternally transferred hormones (hereafter 'maternal hormones'), potentially increasing offspring survival in the predicted conditions (adaptive maternal effects, 1, 2-4). Maternal hormone-mediated effects have been recently highlighted as a potential mechanism and source of phenotypic plasticity to respond to changing climate (5-7), yet empirical evidence is scarce. Experimental studies on hormone-mediated maternal effects have revealed increasingly contradictory results, for example, elevated maternal androgens both increasing, decreasing or having no effect on offspring growth (3). One obvious explanation for such contrasting effects is linked to the well-known pleiotropic effects of (maternal) hormones, due to which prenatal hormone exposure brings both costs (e.g. reduced immune response) and benefits (e.g. faster growth). Therefore, the final fitness outcome is likely to be determined by the potential benefit-cost balance being set by environmental conditions (3).

Studies on context-dependent effects of maternal hormones have been repeatedly called for in the literature, but still only few empirical studies are available. In the most studied maternal hormone group, glucocorticoids, fitness effects depend on the matching between maternal and offspring environment (e.g. 8, 9), such as maternal condition (e.g. $(10,11)$, density $(12)$ and predictability of food (13). In the rare example on maternal androgen hormones, Muriel et al. (14) suggest that the effects of maternal androgens on nestling development and immunity depend on the timing (first or second clutch) of breeding and associated food conditions. To our knowledge, the context-dependent effects of other key maternal hormones, such as thyroid hormones, have not been explored. Yet, characterizing context-dependent effects can contribute to our understanding on the cause of the observed large variation in maternal hormone transfer across and within populations $(4,15)$ and its potential adaptive function.

We previously reported contrasting effects of maternal thyroid hormones (THs: T3=triiodothyronine, $\mathrm{T} 4=$ =thyroxine) on offspring phenotype in two closely related species, the collared flycatcher (Ficedula albicollis) and pied flycatcher (F. hypoleuca) $(16,17)$. THs increased early growth, 
bioRxiv preprint doi: https://doi.org/10.1101/2020.05.08.083725; this version posted May 10,2020 . The copyright holder for this preprint (which was not certified by peer review) is the author/funder, who has granted bioRxiv a license to display the preprint in perpetuity. It is made available under aCC-BY-NC-ND 4.0 International license.

but decreased growth during the second week post-hatching in collared flycatchers (16), while they tended to increase growth during the second week post-hatching in pied flycatchers (17). The underlying mechanisms and the explanations for these contrasting results remain unknown, but one hypothesis could be that the effects of elevated yolk THs would depend on the post-hatching environmental conditions. For example, if prenatal THs increase resting metabolic rate (RMR), as reported in Hsu et al. (18), the elevated RMR may lead to increased growth in benign conditions, but decreased growth when resource availability is poor (19). Moreover, THs have conserved function in controlling thermoregulation (20), which is not fully developed in altricial offspring until late postnatal stage (21). If prenatal THs are expected to increase metabolic rates and stimulate thermogenesis, they may benefit nestling survival in low developmental temperatures, while in higher temperatures such effects may not be observable or even turn negative because of higher energy expenditure. Therefore, experimental tests on whether the effects of yolk THs would depend on post-hatching environmental conditions are now duly required.

Here, we use a full factorial experimental design to, for the first time, study whether maternal THs exert context-dependent effects on early-life phenotype, survival and physiology. We experimentally manipulated both egg TH levels and post-hatching nest-box temperature in a wild population of pied flycatchers. We chose to study interactions between THs and temperature variation, because both factors are involved in thermoregulation $(7,20)$, which is crucial for early-life altricial nestlings $(21)$. Moreover, we previously found that yolk T4 are higher under relatively lower ambient temperature in passerines (22). Testing whether yolk THs have temperature-dependent effects therefore would provide information on whether elevated T4 transfer under lower temperatures could be an adaptive allocation. In addition to measuring postnatal growth and short-term survival (fledging success), we explored changes in potential underlying physiological mechanisms. (i) We measured circulating THs to track any lasting effects of prenatal TH manipulation on the general function of the hormonal axis (18) and to assess the direct effects of postnatal temperature on THs. (ii) We estimated mitochondrial density (i.e. mitochondrial DNA copy number) as a proxy for the effects of our treatments on cellular 
bioenergetics (23). Mitochondria are the powerhouse of cells, converting nutrients into ATP to sustain cellular functions. Mitochondrial density and bioenergetics are likely to be influenced by THs across taxa $(24,25$, reviewed in 26$)$ and by ambient temperature (27). However, to our knowledge, the effects of prenatal THs on mitochondria have not been characterized beyond mammalian models (28). Finally, we measured (iii) biomarkers of oxidative stress, the imbalance between oxidizing molecules (e.g. reactive oxygen species, ROS) and antioxidant protection, which ultimately leads to oxidative damage on biomolecules and cellular dysfunction (29). Elevated yolk THs may result in increased oxidative stress directly via the stimulating effects of THs on metabolism and mitochondrial ROS production (30), or indirectly via increasing developmental speed since fast growth is likely to increase oxidative stress (31). Temperature is also likely to influence oxidative stress since both cold and heat stress have been shown to increase oxidative damage levels (32, e.g. 33).

We summarize our predictions in Table 1. Overall, we predicted that elevated prenatal THs should increase survival in cooler (non-heated) nests, for example due to its stimulating and positive effects on thermogenesis, which might also facilitate growth. On the other side, the increased metabolism in nestlings from heated nests might lead to higher energy expenditure, which albeit not necessarily decreasing survival, but might reduce growth (e.g. 18). We predict that elevated prenatal THs increase postnatal circulating THs and the effect may be stronger in cooler (non-heated) nests. Mitochondrial density is predicted to be increased by the stimulating effect of (prenatal) THs and low temperature, and thus being highest in the nestlings from $\mathrm{TH}$-injected eggs and non-heated nests. Finally, oxidative damage is also predicted to be higher in prenatal TH elevation group (see above), which could be more pronounced in heated nests due to maladaptive thermogenesis enhancement.

\section{Material and methods}

The experiments were conducted under licenses from the Animal Experiment Board of the Administrative Agency of South Finland (ESAVI/2902/2018) and the Environmental Center of Southwestern Finland (license number VARELY549/2018). We conducted our experiment in a nest- 
bioRxiv preprint doi: https://doi.org/10.1101/2020.05.08.083725; this version posted May 10,2020 . The copyright holder for this preprint (which was not certified by peer review) is the author/funder, who has granted bioRxiv a license to display the preprint in perpetuity. It is made available under aCC-BY-NC-ND 4.0 International license.

box population of pied flycatchers located in Turku, Finland $\left(60^{\circ} 25^{\prime} \mathrm{N}, 22^{\circ} 10^{\prime} \mathrm{E}\right)$. Egg THs were manipulated in unincubated eggs using injections in the yolk, following $(17,34)$. All eggs of a nest received the same injection of either thyroid hormones (hereafter, $\mathrm{TH}$ clutches, $\mathrm{N}=30$ clutches) or only vehicle (hereafter, $\mathrm{CO}$ clutches, $\mathrm{N}=30$ clutches). Hatching success was not affected by the hormone treatment (CO: 71.1\%, TH: $64.9 \%, z=-1.129, p=0.259)$.

On the second day after hatching (d2), chicks were individually identified by nail clipping and $c a$. half of the chicks of each nest were swapped among broods with different hormone treatments whenever possible, to create nests which included both $\mathrm{CO}$ and TH treated nestlings. Internal temperature of the nest boxes was then increased between postnatal day 2 and day 8 in $c a$. half of the boxes (hereafter, 'heated nests', $N=24$ ) using heating pads (UniHeat $72 \mathrm{~h}, \mathrm{USA}$ ), installed under the ceiling, and replaced every $2^{\text {nd }}$ day. The period of 2 to 8 days was selected as pied flycatcher nestlings are not fully thermoregulatory during this period, and thus sensitive to variation in ambient temperature (35). The other half served as controls (hereafter 'non-heated nests', $N=23$ nests) and received non-functional heating pads and similar visits every $2^{\text {nd }}$ day. The sample sizes in the four treatment groups at day 2 are: $\mathrm{CO}+$ non-heated $76, \mathrm{CO}+$ heated $50, \mathrm{TH}+$ non-heated 58 , and $\mathrm{TH}+$ heated 53 nestlings, respectively. The actual temperature within the boxes was recorded with a thermologger (iButton thermochron, measuring at $3 \mathrm{~min}$ intervals, $0.0625^{\circ} \mathrm{C}$ accuracy), placed inside all nest boxes at $5 \mathrm{~cm}$ distance above the nest rim, and the average daily temperature between $\mathrm{d} 2$ and $\mathrm{d} 8$ was calculated. The heating treatment increased the temperature by $2.75 \stackrel{\circ}{\circ}$ ( $S E=0.37$, marginal means \pm SEs controlled for date and iButton position: heated $21.25 \pm 0.36$, non-heated $18.50 \pm 0.35$, GLM, t=-7.40, p<0.001, Fig. S1).

Female can be actively brooding until the nestlings are ca. 6-7 days old (35). To account for potential behavioral changes of the female linked to the heating treatment that could influence offspring traits (potentially mask any effect of the heating treatment), we collected data on brooding behavior on $\mathrm{d} 4$ after hatching. We recorded the percentage of time spent brooding during a minimum of 2 hours, using miniature video cameras (ca $4 \times 4 \mathrm{~cm}$, DashCam, UK) mounted at $c a .2 \mathrm{~m}$ distance from 
the nest-boxes ( $N_{\text {non-heated }}=16, N_{\text {heated }}=13$ ). Females brooded $c a .33 \%$ of the time, but the variation was large (SD 16\%) and there was no significant difference in brooding behavior between the treatments (mean $\pm S D$ : non-heated nests $34.7 \pm 16.3 \%$; heated nests $36.3 \pm 15.8 \% ; t=0.58, p=0.57$ ), suggesting that any potential effect of the heating treatment would not be influenced by parental behavior. This data also suggests that during daytime, offspring are exposed to ambient temperatures for substantial periods of time $(60 \%$ of the time at $d 4)$.

Nestling survival was checked at every nest visit (d2, d4, d6, d8, d13). Nestling body mass ( $\sim 0.01 \mathrm{~g}$ ) was recorded at $\mathrm{d} 2, \mathrm{~d} 8$ and $\mathrm{d} 13$ after hatching, and tarsus length $(\sim 0.01 \mathrm{~mm}$, proxy for skeletal

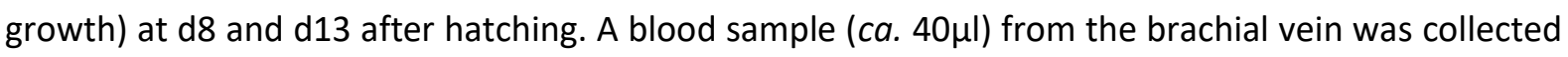
using heparinized capillaries at d13 after hatching and centrifuged before being frozen at $-80^{\circ} \mathrm{C}$. Plasma was used for measuring thyroid hormone concentration (see below). Blood cell pellets were used for extracting DNA to molecularly sex the nestlings and assess mitochondrial density (see ESM for details). Another sample of $c a .20-30 \mu$ whole blood was collected directly in liquid nitrogen and thereafter stored at $-80^{\circ} \mathrm{C}$ to analyze oxidative stress biomarkers.

Plasma T3 and T4 levels were analyzed using nano-LC-MS/MS following previously published methods (36) and are expressed as $\mathrm{ng} / \mathrm{ml}$. Two randomly picked samples per nest were selected due to logistical constraints. Two oxidative stress biomarkers, (i) oxidative damage to lipids (malonaldehyde, MDA, nmol/mg protein, using TBARS assay) and (ii) total glutathione (hereafter $\mathrm{tGSH} ; \mu \mathrm{mol} \mathrm{GSH} / \mathrm{mg}$ protein), the most abundant endogenous intracellular antioxidant, were measured using established protocols, following Sarraude et al. (17). For oxidative stress biomarkers, we excluded the nests whose nestlings were not involved in cross-fostering and the numbers of nestlings analyzed were 179 and 155 at d8 and d13, respectively. Mitochondrial density, estimated through relative mitochondrial DNA copy number, and molecular sexing were analyzed using qPCR on all nestlings survived to d13 ( $n=185)$, following methods in Stier et al. (23) and (37). See ESM for details. 
bioRxiv preprint doi: https://doi.org/10.1101/2020.05.08.083725; this version posted May 10,2020 . The copyright holder for this preprint (which was not certified by peer review) is the author/funder, who has granted bioRxiv a license to display the preprint in perpetuity. It is made available under aCC-BY-NC-ND 4.0 International license.

All statistical models were conducted in the environment of R 3.5.1 ( $R$ core team 2018). We ran separate generalized linear mixed models (GLMMs, package Ime4 and pbkrtest, 38, 39) for each trait of interest to assess the interaction between the treatments of yolk TH injection and nest-box heating, in the meanwhile controlling for relevant covariates and random intercepts to account for potential non-independence among nestlings. The final sample sizes varied by traits due to both the logistical constraints (see above) and missing values due to random failures in certain assays. The exact sample sizes and model details are reported in ESM. For fledging success, binomial distribution and logit link function were applied. For blood MDA, tGSH, and mtDNA density, data were first In-transformed, and for all models examined, no clear violation on residual normality was visually detected. We found no indications of sex-dependent effects of THs or temperature treatment for any of the response variables (all $F<1.5, p>0.2$ ), and thus those are not discussed further.

\section{Results and Discussion}

To our knowledge, we present the first experimental study on context-dependent effects of maternally transferred THs. We found no clear evidence for temperature-dependent effects of maternal THs on offspring survival (fledging success, CO-non-heated 69.7\% CO-heated 78.0\% TH-nonheated $75.9 \%$ TH-heated $76.9 \%, z=0.156, p=0.876$, Table S1). These results suggest that contrary to our predictions, elevated prenatal THs do not clearly benefit nestlings' survival in colder environment. Egg TH concentrations were previously observed to increase with decreasing ambient temperature in passerines (22). If that was an adaptive allocation, we would expect elevated yolk THs to benefit offspring survival under colder condition, but our results do not provide clear support for such an adaptive explanation.

The growth of offspring (tarsus or body mass) from TH elevated and control eggs was not differentially affected by the postnatal temperature treatments at any of the measured age-points (All $\mathrm{F}<1.30, \mathrm{p}>0.26$, Fig $1 \mathrm{a}$, Table S2, S3). Our results therefore suggest that the previously reported 
bioRxiv preprint doi: https://doi.org/10.1101/2020.05.08.083725; this version posted May 10,2020 . The copyright holder for this preprint (which was not certified by peer review) is the author/funder, who has granted bioRxiv a license to display the preprint in perpetuity. It is made available under aCC-BY-NC-ND 4.0 International license.

discrepancies in the effects of prenatal THs on offspring growth across sister species (collared and pied flycatchers, 16,17$)$, and other altricial birds $(18,40)$ are unlikely driven by context-dependent effects of THs related to early postnatal temperature differences. Yet, there are several possible alternative explanations: (i) The study took place in a relatively warm year, with the average temperature during the nestling phase (June-July) being ca. 2 으 C higher than the averages in the past 15 years (2018: +18.4 o C vs 2003-2018 +16.5 ㄷ). We may expect that the differential effects of THs on growth to be evident only under relatively cold conditions. (ii) Our experimental temperature manipulation was rather small, which could have either been compensated by maternal brooding (though brooding did not seem to differ among the groups) or simply too small to induce measurable changes in growth. In previous studies, ca 5 ㄷ C elevation led to a decrease in body mass in blue tits (Cyanistes caeruleus, 33) and great tits (Parus major, 41, 42) and an increase in body mass in tree swallows (Tachycineta bicolor, 43); (iii) If maternal hormone transfer varies according to environmental context, our egg injection treatment might have resulted in different doses depending on the initial yolk hormone levels. Quantifying egg hormonal content in unmanipulated eggs across experiments, years and contexts is now needed to test this possibility. The logical next steps to test other context-dependent effects of maternal THs would be either to reduce ambient temperature during postnatal development or to manipulate some other environmental factors, such as food availability following similar experimental set-ups.

We aimed to characterize the nestling physiological changes underlying potential contextdependent effects of prenatal THs in response to variation in postnatal ambient temperature. Physiological biomarkers are commonly used as early proxies of responses to environmental variation, and are often sensitive even in cases where effects on growth and (early-life) survival are not visible (e.g. 44, 45). In contrast to our predictions, we observed no apparent differences in the circulating T3 or T4 concentration in nestlings exposed to higher levels of THs prenatally (T3: $F_{1,28.3}=1.553, p=$ $0.223 ; \mathrm{T} 4: \mathrm{F}_{1,34.5}=1.032, \mathrm{p}=0.317$ ), or in interaction with postnatal temperature treatments (hormone $\times$ heating, T3: $F_{1.37 .3}=1.896, p=0.177 ;$ T4: $F_{1,32.1}=0.028, p=0.867$, Fig. 1b,c, Table S4). Yet both T3 
and T4 levels correlated positively with nestling body mass (estimate $\pm \mathrm{SE}, \mathrm{T} 3: 0.196 \pm 0.035, \mathrm{~F}_{1.36 .5}=$ 26.9, $p<0.001 ; T 4: 0.563 \pm 0.219, F_{1,33.2}=5.65, p=0.023$, Table S4). Maternal hormones are suggested to cause long-lasting effects on offspring via changes in the function and sensitivity of the corresponding hormonal axis (3), so-called organizational effects. Changes in hypothalamus-pituitarythyroid (HPT)-axis in response to prenatal THs during embryonic development has been characterized in chicken (46), pigeons (18) as well as mammalian models (reviewed in 47). Our results suggest an absence of such long-term programming effects of the HPT-axis in our study system - however it must be noted that circulating TH levels are highly variable in response to internal and external (food, temperature, circadian) variations $(4,46)$, which could mask potential organizing effects. Experimental challenges with thyrotropin-releasing hormones (TRH) or thyriod-stimulating hormone (TSH) are now needed to test for the effects of prenatal THs on the sensitivity of the HPT-axis in birds.

For the first time, we characterized variation in mitochondrial density in relation to prenatal THs and temperature in birds, and in a wild population. In contrast to our predictions, we did not observe clear context-dependent effects of THs on mtDNA copy number (hormone $\times$ heating, $\mathrm{F}_{1,155.8}=0.55, \mathrm{p}=0.458$, Fig $1 \mathrm{~d}$, Table S5), and also no apparent effect of prenatal TH elevation $\left(F_{1,31.0}=0.739, p=0.397\right.$, Table $\left.S 5\right)$ or heating treatment $\left(F_{1,41.5}=0.003, p=0.958\right.$, Table $\left.S 5\right)$ per se. While THs are known to affect mitochondrial biogenesis and function postnatally $(25,26)$, only one previous study to our knowledge has investigated the effects of prenatal THs on mitochondrial parameters in a hypothyroid rat model. This study found no clear effects of prenatal THs on mitochondrial traits (28). Furthermore, mitochondria are generally responsive to varying (both high and low) ambient temperature (reviewed in 27). The lack of effects of our heating experiment may potentially be explained by the timing of the measurements: mitochondrial density was measured 5 days after the heating treatment had ceased, and given that mitochondrial traits are very plastic (as already shown in this species, 23), the effect of the temperature treatment may have vanished by the time of measurement. Finally, both TH and temperature effects on mitochondrial density could be tissuespecific, and not visible in blood cells. 
We predicted that any effects of the treatments on growth, circulating $\mathrm{TH}$ levels or mitochondria could lead to oxidative stress, due to the altered production of free radicals, and/or antioxidant defenses. In line with the results above, we found no evidence for context-dependent effects of prenatal THs and postnatal temperature on the endogenous antioxidant glutathione or oxidative damage to lipids at the end of the heating period (d8) or at 13 days of age (all $F<1.61, p>$ 0.21, Fig. 1e,f, Table S6, S7). These results support our previous findings where elevated prenatal THs did not appear to influence postnatal oxidative stress biomarkers in birds $(16,17)$. Yet, effects of prenatal THs on oxidative stress could be tissue-dependent and/or only visible during embryo development, which needs to be further tested.

In conclusion, we found no clear evidence for context-dependent effects of prenatal THs depending on the ambient early postnatal temperature, nor support for the hypothesis that higher $\mathrm{TH}$ transfer to eggs in cold conditions benefits offspring in cooler rearing conditions. Our study nevertheless suggests multiple avenues for further research on the potential context-dependence of maternal effects on offspring phenotype and the potential underlying physiological mechanisms. As maternal effect has been suggested to enable rapid adaptation to climate change by providing an additional source of phenotypic plasticity (5-7), it is important to understand their context-dependent effects.

\section{Acknowledgements}

We thank all field assistants, especially Lucas Bousseau and Thomas Rosille and Päivi Kotitalo for their great effort, Janina Stauffer for help with laboratory analysis and Tuija Koivisto for analyzing the brooding videos. Turku Biocenter Finland supported the facilities for thyroid hormone measurements.

\section{Competing interests}

The authors declare having no competing interests.

\section{Author contribution}


BYH, AS \& SR designed the study and conducted the fieldwork. All authors contributed to data analysis.

BYH conducted the final statistical analysis. AS, NCS, MC \& SR conducted laboratory work. BYH, AS \& SR wrote the manuscript, with input from TS, MC and NCS.

\section{Funding}

The project was funded by an Academy of Finland grant (\# 286278) to SR. BYH was supported by a grant from Ella and Georg Ehrnrooth Foundation, TS by a grant from the University of Groningen, NCS by Erasmus+, Boussole Grand Est and EDUFI (TM-19-11246) grants, MC by Erasmus+ and Boussole Grand Est grants, and AS by a 'Turku Collegium for Science and Medicine' Fellowship.

\section{Data accessibility}

All data will be archived and available in Dryad upon acceptance. Data is included as supplementary files ( $x x-x x)$. 


\section{References}

1. Moore MP, Whiteman HH, Martin RA. 2019. A mother's legacy: the strength of maternal effects in animal populations. Ecology Letters 22:1620-1628.

2. Yin JJ, Zhou M, Lin ZR, Li QSQ, Zhang YY. 2019. Transgenerational effects benefit offspring across diverse environments: a meta-analysis in plants and animals. Ecology Letters 22:19761986.

3. Groothuis TGG, Hsu BY, Kumar N, Tschirren B. 2019. Revisiting mechanisms and functions of prenatal hormone-mediated maternal effects using avian species as a model. Philosophical Transactions of the Royal Society B-Biological Sciences 374:9.

4. Ruuskanen S, Hsu BY. 2018. Maternal Thyroid Hormones: An Unexplored Mechanism Underlying Maternal Effects in an Ecological Framework. Physiological and Biochemical Zoology 91:904-916.

5. Meylan S, Miles DB, Clobert J. 2012. Hormonally mediated maternal effects, individual strategy and global change. Royal Society Philosophical Transactions Biological Sciences 367:1647-1664.

6. Donelson JM, Salinas S, Munday PL, Shama LNS. 2018. Transgenerational plasticity and climate change experiments: Where do we go from here? Global Change Biology 24:13-34.

7. Ruuskanen S, Hsu B-Y, Nord A. 2020. Endocrinology of thermoregulation of birds in a changing climate. Molecular and Cellular Endocrinology.

8. Sheriff MJ, Bell A, Boonstra R, Dantzer B, Lavergne SG, McGhee KE, MacLeod KJ, Winandy L, Zimmer C, Love OP. 2017. Integrating Ecological and Evolutionary Context in the Study of Maternal Stress. Integrative and Comparative Biology 57:437-449.

9. Schoech SJ, Rensel MA, Heiss RS. 2011. Short- and long-term effects of developmental corticosterone exposure on avian physiology, behavioral phenotype, cognition, and fitness: A review. Current Zoology 57:514-530.

10. Love OP, Williams TD. 2008. The adaptive value of stress-induced phenotypes: Effects of maternally derived corticosterone on sex-biased investment, cost of reproduction, and maternal fitness. American Naturalist 172:E135-E149.

11. Weber BM, Bowers EK, Terrell KA, Falcone JF, Thompson CF, Sakaluk SK. 2018. Pre- and postnatal effects of experimentally manipulated maternal corticosterone on growth, stress reactivity and survival of nestling house wrens. Functional Ecology 32:1995-2007.

12. Dantzer B, Newman AEM, Boonstra R, Palme R, Boutin S, Humphries MM, McAdam AG. 2013. Density Triggers Maternal Hormones That Increase Adaptive Offspring Growth in a Wild Mammal. Science 340:1215-1217.

13. Zimmer C, Boogert NJ, Spencer KA. 2013. Developmental programming: Cumulative effects of increased pre-hatching corticosterone levels and post-hatching unpredictable food availability on physiology and behaviour in adulthood. Hormones and Behavior 64:494-500.

14. Muriel J, Salmon P, Nunez-Buiza A, de Salas F, Perez-Rodriguez L, Puerta M, Gil D. 2015. Context-dependent effects of yolk androgens on nestling growth and immune function in a multibrooded passerine. Journal of Evolutionary Biology 28:1476-1488.

15. Gil D. 2008. Hormones in avian eggs: Physiology, ecology and behavior, p 337-398, Advances in the Study of Behavior, Vol 38, vol 38.

16. Hsu BY, Doligez B, Gustafsson L, Ruuskanen S. 2019. Transient growth-enhancing effects of elevated maternal thyroid hormones at no apparent oxidative cost during early postnatal period. Journal of Avian Biology 50:e01919.

17. Sarraude T, Hsu B-Y, Groothuis T, Ruuskanen S. 2020. Manipulation of prenatal thyroid hormones does not influence growth or physiology in nestling pied flycatchers. Physiological and Biochemical Zoology. 
18. Hsu BY, Dijkstra C, Darras VM, de Vries B, Groothuis TGG. 2017. Maternal thyroid hormones enhance hatching success but decrease nestling body mass in the rock pigeon (Columba livia). General and Comparative Endocrinology 240:174-181.

19. Auer SK, Salin K, Rudolf AM, Anderson GJ, Metcalfe NB. 2015. The optimal combination of standard metabolic rate and aerobic scope for somatic growth depends on food availability. Functional Ecology 29:479-486.

20. McNabb FMA. 2007. The hypothalamic-pituitary-thyroid (HPT) axis in birds and its role in bird development and reproduction. Critical Reviews in Toxicology 37:163-193.

21. Price ER, Dzialowski EM. 2018. Development of endothermy in birds: patterns and mechanisms. Journal of Comparative Physiology B-Biochemical Systemic and Environmental Physiology 188:373-391.

22. Ruuskanen S, Groothuis TGG, Schaper SV, Darras VM, de Vries B, Visser ME. 2016. Temperature-induced variation in yolk androgen and thyroid hormone levels in avian eggs. General and Comparative Endocrinology 235:29-37.

23. Stier A, Bize P, Hsu BY, Ruuskanen S. 2019. Plastic but repeatable: rapid adjustments of mitochondrial function and density during reproduction in a wild bird species. Biology Letters 15:5.

24. Lassiter K, Dridi S, Greene E, Kong B, Bottje WG. 2018. Identification of mitochondrial hormone receptors in avian muscle cells. Poultry Science 97:2926-2933.

25. Lanni A, Moreno M, Goglia F. 2016. Mitochondrial Actions of Thyroid Hormone. Comprehensive Physiology 6:1591-1607.

26. Weitzel JM, Iwen KA. 2011. Coordination of mitochondrial biogenesis by thyroid hormone. Molecular and Cellular Endocrinology 342:1-7.

27. Clarke A, Portner HO. 2010. Temperature, metabolic power and the evolution of endothermy. Biological Reviews 85:703-727.

28. Xia TJ, Zhang X, Wang YM, Deng DT. 2018. Effect of maternal hypothyroidism during pregnancy on insulin resistance, lipid accumulation, and mitochondrial dysfunction in skeletal muscle of fetal rats. Bioscience Reports 38:10.

29. Halliwell B, Gutteridge JMC. 2015. Free Radicals in Biology and Medicine. Oxford University Press, New York.

30. Villanueva I, Alva-Sanchez C, Pacheco-Rosado J. 2013. The Role of Thyroid Hormones as Inductors of Oxidative Stress and Neurodegeneration. Oxidative Medicine and Cellular Longevity:15.

31. Stier A, Delestrade A, Zahn S, Arrive M, Criscuolo F, Massemin-Challet S. 2014. Elevation impacts the balance between growth and oxidative stress in coal tits. Oecologia 175:791-800.

32. Stier A, Massemin S, Criscuolo F. 2014. Chronic mitochondrial uncoupling treatment prevents acute cold-induced oxidative stress in birds. Journal of Comparative Physiology B-Biochemical Systems and Environmental Physiology 184:1021-1029.

33. Andreasson F, Nord A, Nilsson JA. 2018. Experimentally increased nest temperature affects body temperature, growth and apparent survival in blue tit nestlings. Journal of Avian Biology 49:14.

34. Podmokla E, Drobniak SM, Rutkowska J. 2018. Chicken or egg? Outcomes of experimental manipulations of maternally transmitted hormones depend on administration method - a meta-analysis. Biological Reviews 93:1499-1517.

35. Lundberg A, Alatalo R. 1992. The pied flycatcher. Poyser, London.

36. Ruuskanen S, Hsu BY, Heinonen A, Vainio M, Darras VM, Sarraude T, Rokka A. 2018. A new method for measuring thyroid hormones using nano-LC-MS/MS. Journal of Chromatography B-Analytical Technologies in the Biomedical and Life Sciences 1093:24-30.

37. Chang HW, Cheng CA, Gu DL, Chang CC, Su SH, Wen CH, Chou YC, Chou TC, Yao CT, Tsai CL, Cheng CC. 2008. High-throughput avian molecular sexing by SYBR green-based real-time PCR combined with melting curve analysis. Bmc Biotechnology 8:8. 
38. Bates D, Machler M, Bolker BM, Walker SC. 2015. Fitting Linear Mixed-Effects Models Using Ime4. Journal of Statistical Software 67:1-48.

39. Halekoh U, Hojsgaard S. 2014. Kenward-Roger Approximation and Parametric Bootstrap Methods for Tests in Linear Mixed Models - The R Package pbkrtest. Journal of Statistical Software 59:1-32.

40. Ruuskanen S, Darras VM, Visser ME, Groothuis TGG. 2016. Effects of experimentally manipulated yolk thyroid hormone levels on offspring development in a wild bird species. Hormones and Behavior 81:38-44.

41. Rodriguez S, Diez-Mendez D, Barba E. 2016. Negative effects of high temperatures during development on immediate post-fledging survival in Great Tits Parus major. Acta Ornithologica 51:235-244.

42. Rodriguez S, Barba E. 2016. Nestling Growth is Impaired by Heat Stress: an Experimental Study in a Mediterranean Great Tit Population. Zoological Studies 55:13.

43. Dawson RD, Lawrie CC, O'Brien EL. 2005. The importance of microclimate variation in determining size, growth and survival of avian offspring: experimental evidence from a cavity nesting passerine. Oecologia 144:499-507.

44. Stier A, Massemin S, Zahn S, Tissier ML, Criscuolo F. 2015. Starting with a handicap: effects of asynchronous hatching on growth rate, oxidative stress and telomere dynamics in freeliving great tits. Oecologia 179:999-1010.

45. Wikelski M, Cooke SJ. 2006. Conservation physiology. Trends in Ecology \& Evolution 21:3846.

46. Darras VM. 2019. The Role of Maternal Thyroid Hormones in Avian Embryonic Development. Frontiers in Endocrinology 10:10.

47. Huget-Penner S, Feig DS. Maternal thyroid disease and its effects on the fetus and perinatal outcomes. Prenatal Diagnosis:8. 
Fig.1: Effects of prenatal hormone manipulation ( $\mathrm{TH}=$ experimentally elevated yolk thyroid hormone treatment, $\mathrm{CO}=$ control) and postnatal temperature manipulation (non-heated vs. heated nests) on offspring phenotype and physiology. (A) Nestling body mass growth pattern (g, average $\pm S E$ ); (B) plasma triiodothyronine (T3) concentration $(\mathrm{pg} / \mathrm{ml}$, marginal means $\pm \mathrm{SE})$, (C) plasma thyroxine (T4) concentration $(\mathrm{pg} / \mathrm{ml}$, marginal means $\pm \mathrm{SE})$, (D) mitochondrial density in blood cells (In-transformed, marginal means $\pm \mathrm{SE}$ ), $(\mathrm{E})$ blood total glutathione concentration $(\mathrm{tGSH}, \mathrm{nmol} / \mathrm{mg}$ protein, Intransformed means $\pm \mathrm{SE}$ ) and $(\mathrm{F})$ lipid peroxidation (MDA concentration, $\mu \mathrm{mol} / \mathrm{mg}$ protein, Intransformed means $\pm \mathrm{SE}$ ). Heated nests were on average $2.75^{\circ} \mathrm{C}$ warmer than non-heated ones. See text and ESM for details on statistics and sample sizes. 

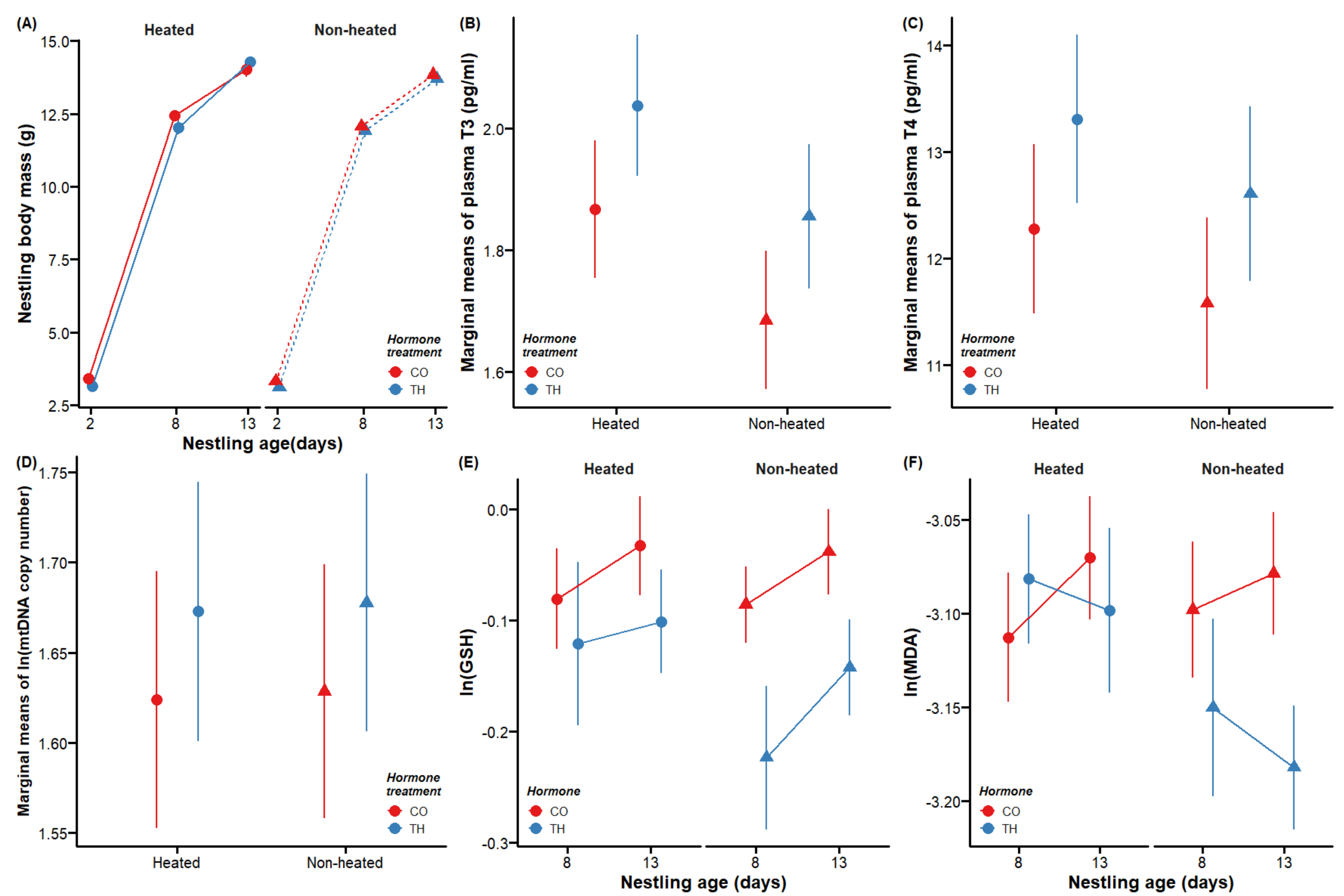
bioRxiv preprint doi: https://doi.org/10.1101/2020.05.08.083725; this version posted May 10,2020 . The copyright holder for this preprint (which was not certified by peer review) is the author/funder, who has granted bioRxiv a license to display the preprint in perpetuity. It is made available under aCC-BY-NC-ND 4.0 International license.

2 Table 1. Summary of the predictions regarding changes in the response variables in relation to

3 elevated prenatal thyroid hormones (THs), postnatal heating and their interaction, i.e. context-

4 dependent effects. $+=$ positive effect of $\mathrm{TH}$ elevation/heating, - = negative effect of $\mathrm{TH}$

5 elevation/heating.

\begin{tabular}{|c|c|c|c|}
\hline Nestling trait & $\begin{array}{l}\text { Prenatal TH } \\
\text { elevation }\end{array}$ & $\begin{array}{l}\text { Postnatal } \\
\text { heating }\end{array}$ & TH $x$ Heating interaction \\
\hline Survival & NA & NA & $\begin{array}{l}\text { Elevated prenatal TH increases nestling } \\
\text { survival in non-heated nests (due to } \\
\text { stimulating effects on } \\
\text { thermoregulation) }\end{array}$ \\
\hline Growth & ? & $?$ & $\begin{array}{l}\text { Elevated prenatal THs decrease } \\
\text { nestling growth in heated nests } \\
\text { (unnecessarily elevated metabolism } \\
\text { caused higher energy expenditure) }\end{array}$ \\
\hline THs & + & - & $\begin{array}{l}\text { Highest in } \mathrm{TH}+\text { non-heated, lowest in } \\
\text { cO-heated }\end{array}$ \\
\hline Mt density & + & - & $\begin{array}{l}\text { Highest in } \mathrm{TH}+\text { non-heated, lowest in } \\
\text { CO-heated }\end{array}$ \\
\hline Oxidative damage & + & $\begin{array}{l}\text { 0/- (low } \\
\text { magnitude) }\end{array}$ & $\begin{array}{l}\text { Highest in TH+heated, lowest in } \\
\text { CO+heated }\end{array}$ \\
\hline
\end{tabular}

6 